\title{
Acupuncture to relieve the pain of thoracotomy: Commentary on randomized, controlled trial
}

\author{
Lee-Yee Chong, PhD, ${ }^{a}$ and Tom Treasure, MD, MS, FRCS, FRCP ${ }^{\mathrm{b}}$
}

See related article on page 1464 .

There are two fundamental principles that in our view should underpin the adoption or continuation of any medical practice. First, we prefer interventions to be based on scientific principles with understandable and demonstrable mechanisms. Second, we expect the beneficial effects to be reproducible and, when tested in a suitably designed study, attributable to the intervention.

If a proposed therapy passes both these tests, we will accept it, whether it is a drug found in nature (herbal remedy) or a physical therapy (massage or manipulation). Thus if a therapy that is new (or new to us) has a large effect that is closely related in time with a cogent mechanism, it is likely to be accepted readily. ${ }^{1}$ If it fails the first criterion, we could still accept it according to the second, but then the standard of unbiased evaluation required would probably be higher. If it cannot pass either form of scrutiny, why should we accept it? An assertion by the practitioner that it works or by patients that they perceive benefit is insufficient. All proposed treatments should be amenable to evaluation, and if effective they should be accepted whatever their origins. We could then drop the labels "alternative" and "complementary." When there are strong associations between the therapy and the therapist, this creates problems in blinding and in interpreting the treatment effect, but these problems already have to be addressed for trials of surgery, physiotherapy, and psychotherapy. ${ }^{2}$

Acupuncture can be considered according to these principles. Is there a mechanism that, on the basis of present knowledge, makes acupuncture a likely means of diminishing thoracotomy pain? It is quite plausible that stimulation of ascending nerve fibers could create sufficient interference with the passage of painful stimuli, through known or as yet unknown neuropharmacologic mechanisms, and that pain would thus be blocked. We know that distraction reduces the impact of pain, whereas if the pain is associated with anxiety about its implications, an otherwise minor irri-

\footnotetext{
From the National Collaborating Centre for Acute Care, Clinical Effectiveness Unit, Royal College of Surgeons, ${ }^{\mathrm{a}}$ and the Clinical Operational Research Unit, Department of Mathematics, University College London, ${ }^{\mathrm{b}}$ London, UK.

Received for publication Aug 14, 2008; accepted for publication Aug 23, 2008.

Address for reprints: Tom Treasure, MD, MS, FRCS, FRCP, Clinical Operational Research Unit, UCL (Department of Mathematics), 4 Taviton St, London WC1H 0BT,

UK (E-mail: tom.treasure@gmail.com).

J Thorac Cardiovasc Surg 2008;136:1470-1

$0022-5223 / \$ 34.00$

Copyright (c) 2008 by The American Association for Thoracic Surgery doi:10.1016/j.jtcvs.2008.08.039
}

tation can dominate the mind. We know that endorphins are released under a range of triggering circumstances and that we can engender delivery of our own doses of endogenous opiates. Because we do not at present recognize a convincing explicative mechanism under the exact circumstances of thoracotomy, however, acupuncture as pain relief for this surgery remains open to question. It has therefore rightly been put to the second test.

In their carefully performed study, the Memorial SloanKettering team ${ }^{3}$ have subjected acupuncture to a randomized, controlled trial. The "special acupuncture technique" under evaluation comprehensively failed the test, so this might be considered the end of the discussion. That is not the way these things work. Failure to provide evidence that a treatment works is only one part of altering belief. It appears that in societal terms, what we scientific medics call "evidence" may be one of the less effective ways of convincing others.

Let us revisit the first criterion, the question of a plausible mechanism. There is a belief that acupuncture points can be "stimulated" in many ways apart from needling. These include tapping, pressing, or rubbing the points as in acupressure (tui na in Chinese or shiatsu in Japanese). To needling can be added the effect of warming the points with heat (moxibustion). The Memorial Sloan-Kettering study involves an "embedded needle" variation. This may have evolved from the static positioning of needles, which are left there for a long time, a technique recorded in Plain Questions: Yellow Emperor's Internal Canon of Medicine, an ancient Chinese text. ${ }^{4}$ But how far can one depart from the original treatment and still accept the putative mechanism as plausible? Suppose a practitioner of traditional ethnic medicine took penicillin powder and modified the administration of the drug and, to suit local ways of doing things, put it in an incense burner at the patient's bedside. Would we accept failure as proof that penicillin is ineffective?

In the acupuncture we have observed in China, the needles are long and fine-not remotely like these modified tin tacks left under the dressings. Chinese acupuncturists treat many patients with Bell's palsy (translated for us as "wind stroke") and report a high cure rate. We know that Bell's palsy remits spontaneously, and that it does so at about the same rate without acupuncture. Is it not like doctors the world over to believe that all positive outcomes can be claimed as results of the treatment? A doctor (observed on a visit to China by T.T.) noted that one patient among several with facial palsy had a furrowed brow, which she told us marked his illness as not being a case of wind stroke. Although she would not have made the distinction 
between upper and lower motor neurons, she did recognize it as a different disease. She said that her treatment would not work; however, he had come to her with hope of cure, so she would treat him just the same so as not to disappoint him. How like western medicine that is too! So often we hear in justification of the administration of cancer therapies with small or unlikely benefits that "at least it gives hope."

There is another important missing component relative to the acupuncture that we observed in China. In China, the doctor personally administered each needle and talked to the patient constantly. Acupuncture, like so many alternative therapies, has a large component of interaction between patient and practitioner, and patients welcome this. Many prefer the experience to what can become an impersonal form of care in our evidence-based medicine, and as a result they vote with their feet. Many (we might think foolishly) prefer to go to quacks, but they have a reason-they get more time, more attention, and perhaps less loftiness from these practitioners.

A recent multicenter, randomized trial of sham acupuncture in irritable bowel syndrome concluded, "Our study has important implications for routine clinical care and suggests that routine medical care would be less efficient if patientpractitioner interactions were reduced. Based on the results of the present study, a positive patient-practitioner relationship can make a difference." syndrome and other highly subjective disorders consistently report benefit from acupuncture, but in Kaptchuk and colleagues' study, ${ }^{5}$ the technical and talking components of intervention were teased apart. Two groups received identical sham acupuncture with respect to technical aspects, but in one group the talk was kept to a minimum. The practitioners' protocol for the study was to explain that this was "a scientific study" for which they had been "instructed not to converse with patients." The patients who had the usual full commentary on the purpose and expectations of treatment reported more benefit than did those for whom the talk was curtailed, who in turn reported more improvement in symptoms than a control group who remained on a waiting list.

This trial provides an obvious lesson that supportive verbal interaction is helpful to the sick. Under various circumstances, such interaction may be characterized as psychotherapy, placebo, or even mumbo jumbo, but it has an effect. We should not denigrate it or neglect it; we should characterize it better, value it, and price it. ${ }^{6,7}$ Therapists' time costs money, but better to use it because we believe in it and to quantify its benefit than to let it slip in as a cynical exercise in market competition under the guise of complementary medicine. Logically, we might suggest keeping the talk and throwing away the needles; however, if the patient has faith in the needles, they are important to the placebo effect. To deliberately use "sham" treatments in practice would surely be a confidence trick, but it appears that the therapist too must believe-which brings it worryingly close to folie à deux. For an elaboration on these and other points, see the online responses to the study of Kaptchuk and colleagues. ${ }^{8}$

We have one final concern. Cancer surgery is now often used in combination with adjuvant therapies, and the effects of the various components cannot be confidently determined in observational studies. Clinical trials of cancer surgery are scarce and often declared impossible, but pain research is also difficult. The Memorial Sloan-Kettering study on acupuncture $^{3}$ may prompt thoracic surgeons to take up the challenge of putting patients into trials and thus subject their own therapies to formal evaluation. ${ }^{9}$

\section{References}

1. Glasziou P, Chalmers I, Rawlins M, McCulloch P. When are randomised trials unnecessary? Picking signal from noise. BMJ. 2007;334:349-51.

2. Boutron I, Moher D, Altman DG, Schulz KF, Ravaud P. Extending the CONSORT statement to randomized trials of nonpharmacologic treatment: explanation and elaboration. Ann Intern Med. 2008;148:295-309.

3. Deng. Randomized controlled trial of a special acupuncture technique for pain after thoracotomy. J Thorac Cardiovasc Surg. 2008.

4. Qiu ML. Chinese acupuncture and moxibustion. New York: Churchill Livingstone; 1993.

5. Kaptchuk TJ, Kelley JM, Conboy LA, Davis RB, Kerr CE, Jacobson EE, et al Components of placebo effect: randomised controlled trial in patients with irritable bowel syndrome. BMJ. 2008;336:999-1003.

6. Wonderling D. Acupuncture in mainstream health care. BMJ. 2006;333:611-2.

7. Wonderling D, Vickers AJ, Grieve R, McCarney R. Cost effectiveness analysis of a randomised trial of acupuncture for chronic headache in primary care. BMJ. 2004; 328:747.

8. Rapid responses to Kaptchuk, et al. $B M J$ [online]. 2008. Available from: URL: http://www.bmj.com/cgi/eletters/336/7651/999. Accessed September 29, 2008.

9. Rusch VW. Thoracic surgical clinical trials: Y2K and beyond. Ann Thorac Surg. 1999;68:2-3. 